\title{
Stability Indicating RP-HPLC Method Development and Validation for Simultaneous Estimation of Ertugliflozin and Sitagliptin in Bulk and Pharmaceutical Dosage Form
}

\author{
G. Ananya ${ }^{1}$, M. Ajitha ${ }^{2}$
}

${ }^{1}$ M. Pharmacy Scholar, Department of Pharmaceutical Analysis, Institute of Science and Technology, JNTUH, Hyderabad

${ }^{2}$ Professor \& Head, Deputy Director of Academic Audit Cell - JNTUH \& OIE, Center for Pharmaceutical Sciences, JNTUH, Hyderabad

\section{Received: 11-10-2021 / Revised Accepted: 25-11-2021 / Published: 02-01-2022}

\begin{abstract}
A simple, Accurate, precise method was developed for the simultaneous estimation of the Sitagliptin and Ertugliflozin in API and Tablet dosage form. Chromatogram was run through Std Ascentis C18 150 x $4.6 \mathrm{~mm}, 2.7 \mu$. Mobile phase containing Buffer 0.01N Ammonium acetate: Acetonitrile taken in the ratio 60:40 was pumped through column at a flow rate of $0.9 \mathrm{ml} / \mathrm{min}$. Buffer used in this method was $0.01 \mathrm{~N}$ Ammonium acetate. Temperature was maintained at $30^{\circ} \mathrm{C}$. Optimized wavelength selected was $220 \mathrm{~nm}$. Retention time of Sitagliptin and Ertugliflozin were found to be $2.151 \mathrm{~min}$ and $2.722 \mathrm{~min}$. \%RSD of the Sitagliptin and Ertugliflozin were found to be 1.2 and 0.8 respectively. \%Recovery was obtained as $99.99 \%$ and $100.61 \%$ for Sitagliptin and Ertugliflozin respectively. LOD, LOQ values obtained from regression equations of Sitagliptin and Ertugliflozin were $0.69,0.05$ and 2.10, 0.15 respectively. Regression equation of Sitagliptin is $y=28297 x+20644$, and $y=74691 x+$ 2292.1 of Ertugliflozin. Retention times were decreased and that run time was decreased, so the method developed was simple and economical that can be adopted in regular Quality control test in Industries.
\end{abstract}

Key Words: Ertugliflozin, Sitagliptin, RP-HPLC

\section{INTRODUCTION}

Ertugliflozin belongs to the class of potent and selective inhibitors of the sodium-dependent glucose cotransporters (SGLT), more specifically the type 2 which is responsible for about $90 \%$ of the glucose reabsorption from glomerulus. Ertugliflozin is a small inhibitor of the SGLT2 and its activity increases glucose excretion, reducing hyperglycemia without the requirement of excessive insulin secretion. Sitagliptin is a new oral hypoglycemic (anti-diabetic drug) of the new dipeptidyl peptidase-4 (DPP-4) inhibitor class of drugs.

This enzyme-inhibiting drug is to be used either alone or in combination with metformin or

Address for Correspondence: G. Ananya, M. Pharmacy Scholar, Department of Pharmaceutical Analysis, Institute of Science and Technology, JNTUH, Hyderabad.

How to Cite this Article: G. Ananya, M. Ajitha. Stability Indicating RP-HPLC Method Development and Validation for Simultaneous Estimation of Ertugliflozin and Sitagliptin in Bulk and Pharmaceutical Dosage Form. World J Pharm Sci 2022; 10(01): 52-58; https://doi.org/10.54037/WJPS.2022.100105 
thiazolidinedione for control of type 2 diabetes mellitus. The drug works to competitively inhibit a protein/enzyme, dipeptidyl peptidase 4 , that results in an increased amount of active incretins (GLP-1 and GIP), reduced amount of release of glucagon (diminishes its release) and increased release of insulin. A simple, precise, accurate RP-HPLC method was developed for simultaneous estimation of Ertugliflozin and Sitagliptin.

\section{MATERIALS AND METHODS}

Materials: Ertugliflozin and Sitagliptin pure drugs (API), Combination Ertugliflozin and Sitagliptin tablets (STEGLUJAN), Distilled water, Acetonitrile, Phosphate buffer, Methanol, Potassium dehydrogenate ortho phosphate buffer, Ortho-phosphoric acid. All the above chemicals and solvents are from Rankem

\section{Instruments and chromatographic conditions}

Electronics Balance-Denver, $\mathrm{p}^{\mathrm{H}}$ meter -BVK enterprises, India, Ultrasonicator-BVK enterprises, WATERS HPLC 2695 SYSTEM equipped with quaternary pumps, Photo Diode Array detector and Auto sampler integrated with Empower 2 Software., UV-VIS spectrophotometer PG Instruments T60 with special bandwidth of $2 \mathrm{~mm}$ and $10 \mathrm{~mm}$ and matched quartz cells integrated with UV win 6 Software was used for measuring absorbances of Ertugliflozin and Sitagliptin solutions. The mobile phase used was 0.01NAmmonium acetate:Acetonitrile(60:40), at a flow rate of $0.9 \mathrm{ml} / \mathrm{min}$, samples were analyzed at $220 \mathrm{~nm}$ detector wavelength and at an injection volume of $10 \mu \mathrm{L}$ using Ascentis C18( $4.6 \times 150 \mathrm{~mm}$, $2.7 \mu \mathrm{m}$ ) with run time of $8 \mathrm{~min}$.

\section{Methods:}

Diluent: Based up on the solubility of the drugs, diluent was selected, Acetonitrile and Water taken in the ratio of 50:50

Buffer: $0.1 \%$ OPA Buffer (1 $\mathrm{ml}$ of Conc Ortho Phosphoric acid was diluted to 1000 mlwith water).

\subsection{N Ammonium acetate}

Accurately weighed $0.77 \mathrm{gm}$ of Ammonium acetate in a $1000 \mathrm{ml}$ of Volumetric flask add about $900 \mathrm{ml}$ of milli-Q water added and degas to sonicate and finally make up the volume with water to get $0.01 \mathrm{~N}$ Ammonium acetate buffer.

Preparation of Standard stock solutions: Accurately weighed $2.5 \mathrm{mg}$ of Ertugliflozin, 50mg of Sitagliptin and transferred to individual $50 \mathrm{ml}$ volumetric flasks separately. 3/4 th of diluents was added to both of these flasks and sonicated for 10 minutes. Flasks were made up with diluents and labeled as Standard stock solution 1and 2 . $(50 \mu \mathrm{g} / \mathrm{ml}$ of Ertugliflozin and $1000 \mu \mathrm{g} / \mathrm{ml}$ of Sitagliptin)

Preparation of Standard working solutions (100\% solution): $1 \mathrm{ml}$ from each stock solution was pipetted out and taken into a $10 \mathrm{ml}$ volumetric flask and made up with diluent. $(5 \mu \mathrm{g} / \mathrm{ml}$ Ertugliflozin of and $100 \mu \mathrm{g} / \mathrm{ml}$ of Sitagliptin)

Preparation of Sample stock solutions: 5 tablets were weighed and the average weight of each tablet was calculated, then the weight equivalent to 1 tablet was transferred into a $10 \mathrm{ml}$ volumetric flask, $5 \mathrm{ml}$ of diluents was added and sonicated for 25 min, further the volume was made up with diluent and filtered by HPLC filters $(50 \mu \mathrm{g} / \mathrm{ml}$ of Ertugliflozin and $1000 \mu \mathrm{g} / \mathrm{ml}$ of Sitagliptin)

Preparation of Sample working solutions $(\mathbf{1 0 0 \%}$ solution): $1 \mathrm{ml}$ of filtered sample stock solution was transferred to $10 \mathrm{ml}$ volumetric flask and made up with diluent. $(5 \mu \mathrm{g} / \mathrm{ml}$ of Ertugliflozin and $100 \mu \mathrm{g} / \mathrm{ml}$ of Sitagliptin)

\section{Method Validation:}

As per ICH guidelines the method was validated and the parameters like Linearity, Specificity, Accuracy, Precision, Limit of Detection (LOD) and Limit of Quantitation (LOQ) were assessed.

Specificity: checking of interferences in the optimized method. We should not find interfering peaks in blank and placebo at retention times of these drugs in this method. So this method was said to be specific.

Linearity: Stock solutions of Ertugliflozin and Sitagliptin is taken in to 6 different volumetric flasks and diluted to $10 \mathrm{ml}$ with diluents. Linearity solutions are prepared such that $0.25,0.5,0.75,1$, $1.25,1.5 \mathrm{ml}$

Accuracy: Preparation of Standard stock solutions: Accurately weighed $2.5 \mathrm{mg}$ of Ertugliflozin, $50 \mathrm{mg}$ of Sitagliptin and transferred to individual $50 \mathrm{ml}$ volumetric flasks separately. 3/4 th of diluents was added to both of these flasks and sonicated for 10 minutes. Flasks were made up with diluents and labeled as Standard stock solution 1and 2 . $(50 \mu \mathrm{g} / \mathrm{ml}$ of Ertugliflozin and $1000 \mu \mathrm{g} / \mathrm{ml}$ of Sitagliptin)

Preparation of $50 \%$ Spiked Solution: $0.5 \mathrm{ml}$ of sample stock solution was taken into a $10 \mathrm{ml}$ volumetric flask, to that $1.0 \mathrm{ml}$ from each standard stock solution was pipetted out, and made up to the mark with diluent.

Preparation of $100 \%$ Spiked Solution: $1.0 \mathrm{ml}$ of sample stock solution was taken into a $10 \mathrm{ml}$ 
volumetric flask, to that $1.0 \mathrm{ml}$ from each standard stock solution was pipetted out, and made up to the mark with diluent.

Preparation of $150 \%$ Spiked Solution: $1.5 \mathrm{ml}$ of sample stock solution was taken into a $10 \mathrm{ml}$ volumetric flask, to that $1.0 \mathrm{ml}$ from each standard stock solution was pipetted out, and made up to the mark with diluents.

Robustness: Small deliberate changes in method like Flow rate, mobile phase ratio, and temperature are made but there were no recognized change in the result and are within range as per ICH Guide lines. Robustness conditions like Flow minus $(0.8 \mathrm{ml} / \mathrm{min})$, Flow plus $(1.0 \mathrm{ml} / \mathrm{min})$, mobile phase minus, mobile phase plus, temperature minus $\left(25^{\circ} \mathrm{C}\right)$ and temperature plus $\left(35^{\circ} \mathrm{C}\right)$ was maintained and samples were injected in duplicate manner. System suitability parameters were not much affected and all the parameters were passed. \%RSD was within the limit.

LOD sample Preparation: $0.25 \mathrm{ml}$ each from two standard stock solutions was pipetted out and transferred to two separate $10 \mathrm{ml}$ volumetric flasks and made up with diluents. From the above solutions $0.1 \mathrm{ml}$ each of Ertugliflozin, Sitagliptin, solutions respectively were transferred to $10 \mathrm{ml}$ volumetric flasks and made up with the same diluents

LOQ sample Preparation: $0.25 \mathrm{ml}$ each from two standard stock solutions was pipetted out and transferred to two separate $10 \mathrm{ml}$ volumetric flask and made up with diluent. From the above solutions $0.3 \mathrm{ml}$ each of Ertugliflozin, Sitagliptin, and solutions respectively were transferred to $10 \mathrm{ml}$ volumetric flasks and made up with the same diluent.

\section{System suitability parameters:}

The system suitability parameters were determined by preparing standard solutions of Ertugliflozin $(5 \mathrm{ppm})$ and Sitagliptin (100ppm) and the solutions were injected six times and the parameters like peak tailing, resolution and USP plate count were determined. The \% RSD for the area of six standard injections results should not be more than $2 \%$.

Assay: Assay of the marketed formulation was carried out by injecting sample corresponding to equivalent weight into HPLC system.

\section{RESULTS AND DISCUSSION}

Optimization of Chromatographic Conditions: To develop and establish a suitable RP-HPLC method for estimation of Ertugliflozin and Sitagliptin in bulk and tablet dosage forms, different preliminary tests were performed and different chromatographic conditions were tested and optimized chromatographic conditions were developed which were given in Table-1. The final analysis was performed by using 0.01NAmmonium acetate: Acetonitrile $(60: 40)$, at a flow rate of $0.9 \mathrm{ml} / \mathrm{min}$, samples were analyzed at $220 \mathrm{~nm}$ detector wavelength and at an injection volume of $10 \mu \mathrm{L}$ using Ascentis C18 (4.6 × 150mm, 2.7 $\mu \mathrm{m})$ with run time of $8 \mathrm{~min}$. The proposed method was optimized to give sharp peaks with good resolution, minimum tailing effect for Ertugliflozin and Sitagliptin, the optimized chromatogram was obtained as shown in (figure-7).

\section{Validation:}

Linearity was established for Sitagliptin (25$150 \mu \mathrm{g} / \mathrm{ml})$ and Ertugliflozin $(1.25-7.5 \mu \mathrm{g} / \mathrm{ml})$ at six different concentrations each were injected in a duplicate manner. Average areas were mentioned and linearity equations obtained for Sitagliptin was $\mathrm{y}=28297 \mathrm{x}+20644$. and of Ertugliflozin was $\mathrm{y}=$ $74691 x+2292.1$. Correlation coefficient obtained was 0.999 for the two drugs. The Linearity calibration curves were plotted as shown in (Figure-3,4). Retention times of Sitagliptin and Ertugliflozin were $2.151 \mathrm{~min}$ and $2.722 \mathrm{~min}$ respectively. We did not found and interfering peaks in blank and placebo at retention times of these drugs in this method. So this method was said to be specific. Three levels of Accuracy samples $50 \%, 100 \%$, $150 \%$ were prepared by standard addition method. Triplicate injections were given for each level of accuracy and mean \% Recovery was obtained as $100.61 \%$ and $99.99 \%$ for Ertugliflozin and Sitagliptin respectively (Table-3). From a single volumetric flask of working standard solution six injections were given and the obtained areas were mentioned. Average area, standard deviation and \% RSD were calculated for two drugs. \% RSD obtained as $1.2 \%$ and $0.8 \%$ respectively for Sitagliptin and Ertugliflozin. $\%$ RSD for Repeatability for both Sitagliptin and Ertugliflozin was obtained as $0.7 \%$. In Intermediate precision \%RSD were calculated for two drugs and obtained as $0.9 \%$ and $1.0 \%$ respectively for Sitagliptin and Ertugliflozin. As the limit of Precision was less than "2" the system precision was passed in this method. The LOD and LOQ values obtained from regression equations of Sitagliptin and Ertugliflozin were 0.69, 0.05 and 2.10, 0.15(Table-4). Robustness conditions like Flow minus $(0.8 \mathrm{ml} / \mathrm{min})$, Flow plus $(1.0 \mathrm{ml} / \mathrm{min})$, mobile phase minus (65B:35A), mobile phase plus (55B:45A), temperature minus $\left(25^{\circ} \mathrm{C}\right)$ and temperature plus $\left(35^{\circ} \mathrm{C}\right)$ was maintained and samples were injected in duplicate manner (Table5). System suitability parameters were not much affected and all the parameters were passed. \%RSD was within the limit. Merck Sharp \& Dohme Corp 
(Steglujan), bearing the label claim Ertugliflozin $100 \mathrm{mg}$, Sitagliptin5mg. Assay was performed with the above formulation. Average \% Assay for Ertugliflozin and Sitagliptin obtained was $100.01 \%$ and $99.20 \%$ respectively (Table-7). The chromatogram of standard drugs and pharmaceutical dosage forms were shown in (Figure-5,6).

\section{Degradation studies:}

Degradation studies were performed with the formulation and the degraded samples were injected. Assay of the injected samples was calculated and all the samples passed the limits of degradation (Table-8).

\section{CONCLUSION}

Chromatographic conditions used are stationary phase Ascentis C18 (4.6 x 150mm, 2.7 $\mu \mathrm{m})$ Mobile phase $0.01 \mathrm{~N}$ Ammonium acetate: Acetonitrile in the ratio of 60:40 and flow rate were maintained at $0.9 \mathrm{ml} / \mathrm{min}$, detection wave length was $220 \mathrm{~nm}$, column temperature was set to $30^{\circ} \mathrm{C}$. Conditions

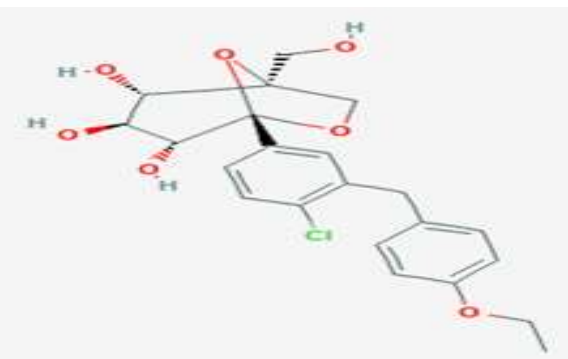

Figure-1: Structure of Ertugliflozin were finalized as optimized method. System suitability parameters were studied by injecting the standard six times and results were well under the acceptance criteria. Linearity study was carried out between $25 \%$ to $150 \%$ levels, $\mathrm{R}^{2}$ value was found to be 0.999 for both Ertugliflozin and Sitagliptin. Precision was found to be 1.2 and 0.8 for Sitagliptin and Ertugliflozin. LOD, LOQ values obtained from regression equations of Sitagliptin and Ertugliflozin were $0.69,0.05$ and 2.10, 0.15 respectively. By using above method assay of marketed formulations was carried out and average \% Assay for Ertugliflozin and Sitagliptin obtained was $100.01 \%$ and $99.20 \%$ respectively. Degradation studies of Ertugliflozin and Sitagliptin were done, in all condition purity threshold was more than purity angle and within acceptable range. Full length method was not performed; if it is done this method can be used for routine analysis of Ertugliflozin and Sitagliptin. Retention times were decreased and that run time was decreased, so the method developed was simple and economical that can be adopted in regular Quality control test in Industries.

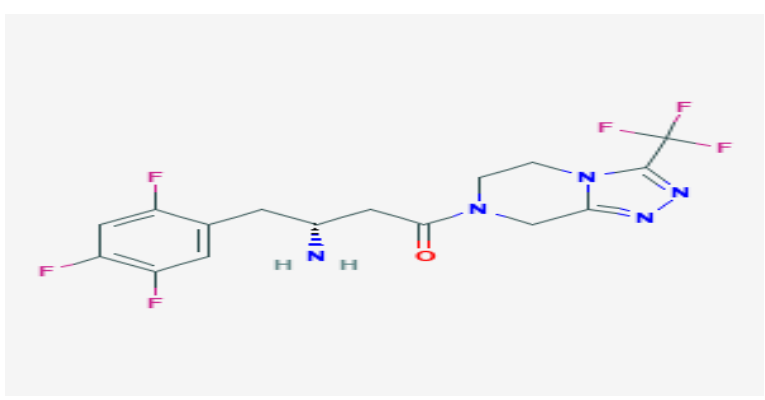

Figure-2: Structure of Sitagliptin

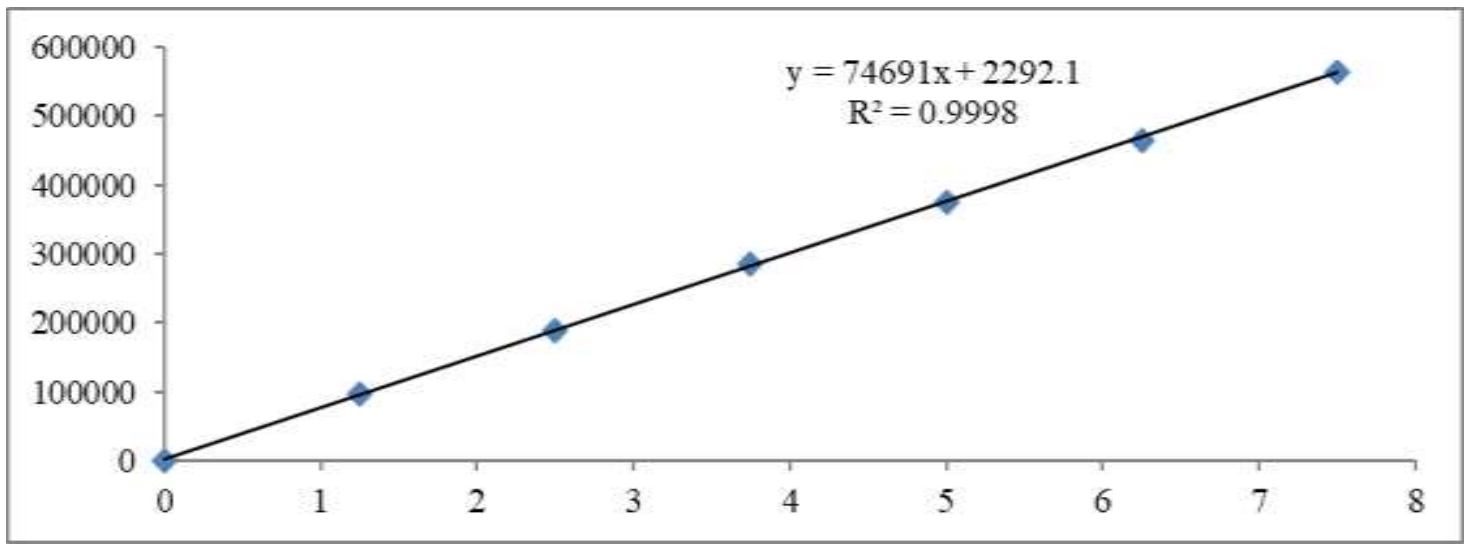

Figure-3: Calibration curve of Ertugliflozin 


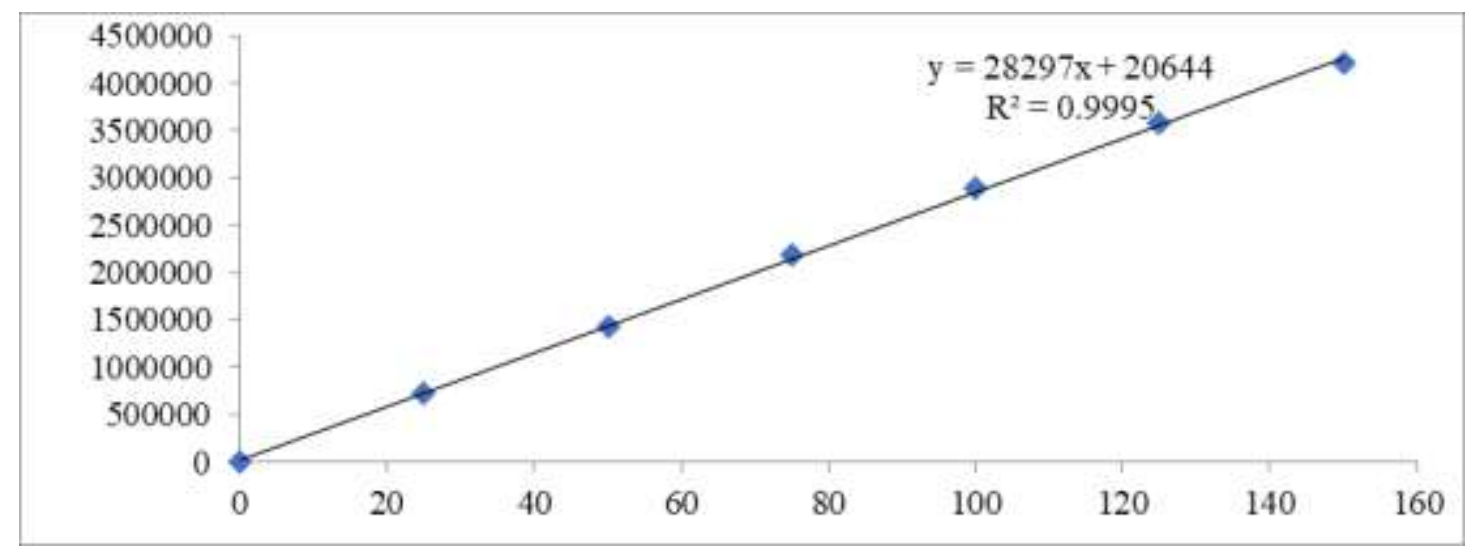

\section{Figure-4: Calibration curve of Sitagliptin}

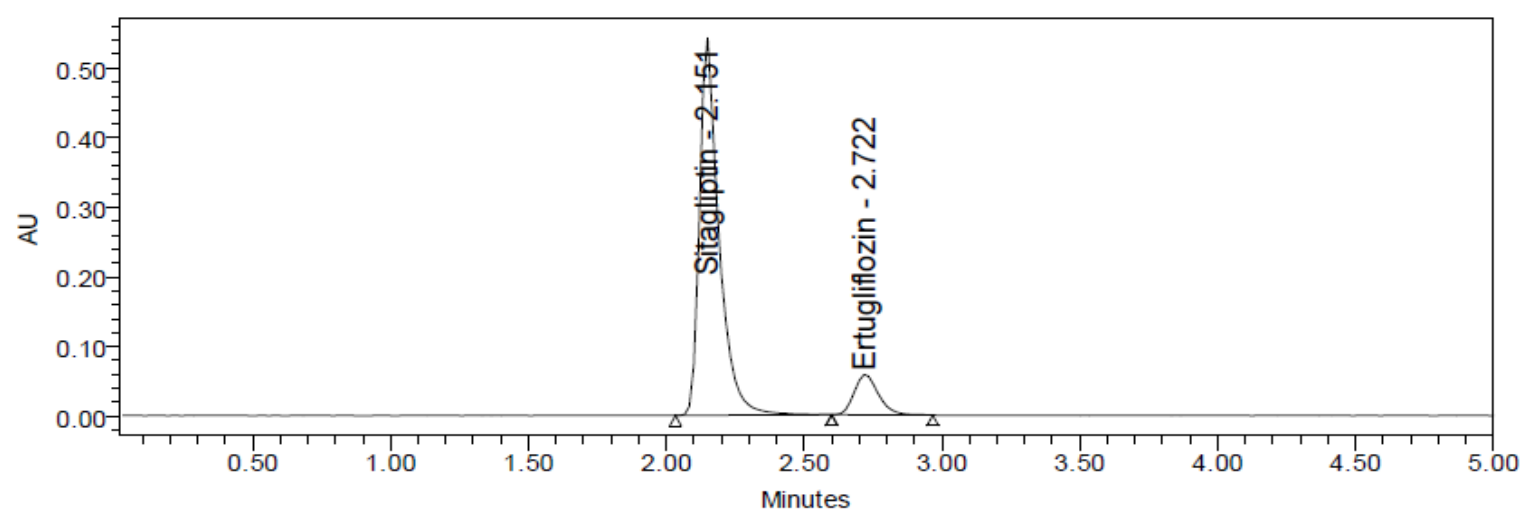

Figure-5: Chromatogram of working standard solution

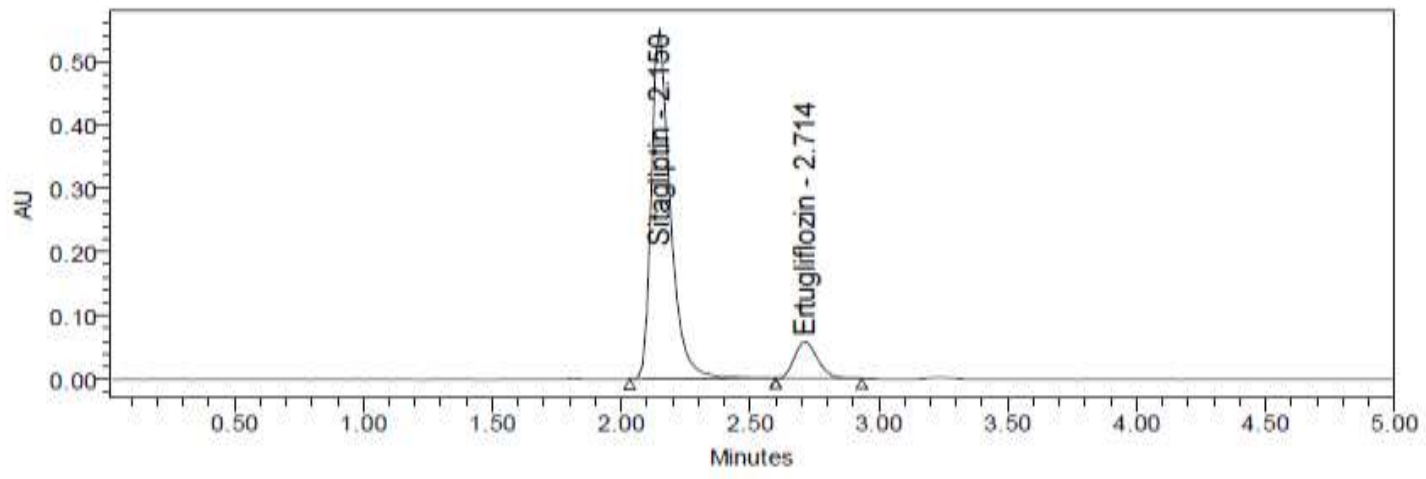

Figure-6: Chromatogram of working sample solution

Table-1: Optimized method Chromatographic conditions:

\begin{tabular}{|l|l|}
\hline Parameter & Condition \\
\hline RP-HPLC & $\begin{array}{l}\text { WATERSHPLC2695 SYSTEM equipped with quarternary pumps, Photo } \\
\text { Diode Array detector and Auto sampler integrated with Empower 2 software }\end{array}$ \\
\hline Mobile phase & $0.01 \mathrm{~N}$ Ammonium acetate:Acetonitrile $(60: 40)$ \\
\hline Flow rate & $0.9 \mathrm{ml} / \mathrm{min}$ \\
\hline Column & Std Ascentis C18 $(4.6 \times 150 \mathrm{~mm}, 2.7 \mu \mathrm{m})$ \\
\hline Detector wavelength & $220 \mathrm{~nm}$ \\
\hline Column temperature & $30^{\circ} \mathrm{C}$ \\
\hline Injection volume & $10 \mu \mathrm{L}$ \\
\hline Run time & $8 \mathrm{~min}$ \\
\hline Diluents & Water and Acetonitrile in the ratio 50:50 \\
\hline Results & $\begin{array}{l}\text { In this trail Both peaks have good resolution, tailing factor, theoretical plate } \\
\text { count and resolution. }\end{array}$ \\
\hline
\end{tabular}




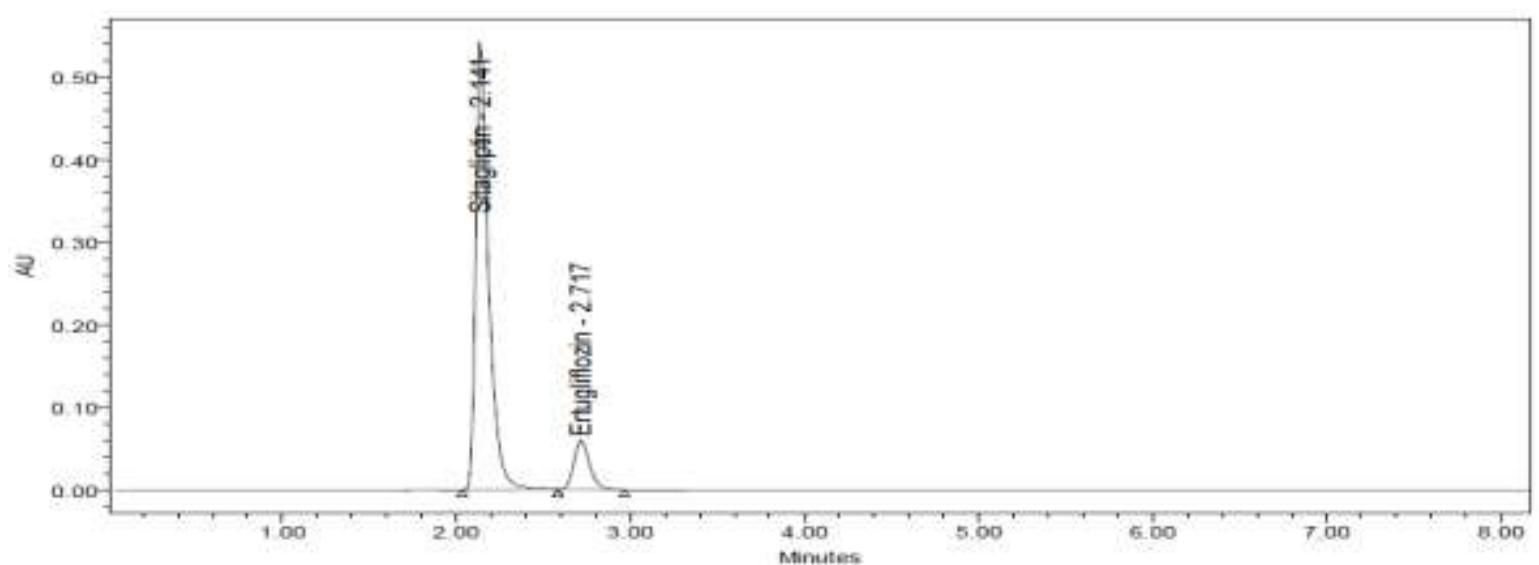

Figure-7: Optimized Chromatogram

Table-2: Precision Results of Sitagliptin and Ertugliflozin

\begin{tabular}{|l|l|l|l|l|l|l|}
\hline \multirow{2}{*}{ S.no } & System precision & \multicolumn{2}{l|}{ Repeatability } & \multicolumn{2}{l|}{ Intermediate precision } \\
\cline { 2 - 7 } & Sitagliptin & Ertugliflozin & Sitagliptin & Ertugliflozin & Sitagliptin & Ertugliflozin \\
\hline $\mathbf{1}$ & 2825809 & 374775 & 2825268 & 375393 & 2808616 & 378860 \\
\hline $\mathbf{2}$ & 2801560 & 373393 & 2830088 & 373699 & 2785129 & 369315 \\
\hline $\mathbf{3}$ & 2879932 & 378963 & 2796786 & 380403 & 2819380 & 372387 \\
\hline $\mathbf{4}$ & 2832040 & 379692 & 2820903 & 376372 & 2798389 & 375833 \\
\hline $\mathbf{5}$ & 2869835 & 375306 & 2792868 & 378549 & 2750301 & 378156 \\
\hline $\mathbf{6}$ & 2795873 & 372335 & 2840886 & 379275 & 2772945 & 377431 \\
\hline mean & 2834775 & 375744 & 2817800 & 377282 & 2789127 & 375330 \\
\hline S.D & 33901.7 & 2974.2 & 19039.7 & 2551.6 & 25164.1 & 3740.5 \\
\hline \%RSD & 1.2 & 0.8 & 0.7 & 0.7 & 0.9 & 1.0 \\
\hline
\end{tabular}

Table-3: Accuracy results of Ertugliflozin (Drug1) and Sitagliptin (Drug2)

\begin{tabular}{|c|c|c|c|c|c|c|c|c|}
\hline \multirow[t]{2}{*}{ \%Level } & \multicolumn{2}{|c|}{$\begin{array}{l}\text { Amount } \\
\operatorname{Spiked}(\mu \mathrm{g} / \mathrm{ml})\end{array}$} & \multicolumn{2}{|c|}{$\operatorname{Amount} \operatorname{Recovered}(\mu \mathrm{g} / \mathrm{ml})$} & \multicolumn{2}{|c|}{ \% Recovery } & \multicolumn{2}{|c|}{ Mean \% Recovery } \\
\hline & Drug 1 & Drug 2 & Drug 1 & Drug 2 & Drug 1 & Drug 2 & Drug 1 & Drug 2 \\
\hline \multirow[t]{3}{*}{$\mathbf{5 0 \%}$} & 2.5 & 50 & 2.521 & 49.701 & 100.82 & 99.40 & \multirow{9}{*}{$100.61 \%$} & \multirow{9}{*}{$99.99 \%$} \\
\hline & 2.5 & 50 & 2.509 & 50.528 & 100.38 & 101.06 & & \\
\hline & 2.5 & 50 & 2.538 & 50.161 & 101.53 & 100.32 & & \\
\hline \multirow[t]{3}{*}{$100 \%$} & 5 & 100 & 5.041 & 99.703 & 100.83 & 99.70 & & \\
\hline & 5 & 100 & 5.025 & 100.809 & 100.51 & 100.81 & & \\
\hline & 5 & 100 & 5.009 & 100.769 & 100.17 & 100.77 & & \\
\hline \multirow[t]{3}{*}{$150 \%$} & 7.5 & 150 & 7.568 & 147.918 & 100.91 & 98.61 & & \\
\hline & 7.5 & 150 & 7.541 & 149.677 & 100.19 & 99.78 & & \\
\hline & 7.5 & 150 & 7.512 & 149.237 & 100.16 & 99.49 & & \\
\hline
\end{tabular}

Table4: LOD and LOQ Values of Sitagliptin and Ertugliflozin

\begin{tabular}{|l|l|l|}
\hline Molecule & LOD & LOQ \\
\hline Sitagliptin & 0.69 & 2.10 \\
\hline Ertugliflozin & 0.05 & 0.15 \\
\hline
\end{tabular}

Table-5: Robustness Data of Ertugliflozin and Sitagliptin

\begin{tabular}{|l|l|l|l|}
\hline S.no & Condition & \%RSD of Ertugliflozin & \%RSD of Sitagliptin \\
\hline 1 & Flow rate $(-) 0.8 \mathrm{ml} / \mathrm{min}$ & 1.0 & 0.2 \\
\hline 2 & Flow rate $(+) 1.0 \mathrm{ml} / \mathrm{min}$ & 1.7 & 0.8 \\
\hline 3 & Mobile phase $(-) 65 \mathrm{~B}: 35 \mathrm{~A}$ & 1.1 & 1.6 \\
\hline 4 & Mobile phase $(+) 55 \mathrm{~B}: 45 \mathrm{~A}$ & 0.6 & 0.6 \\
\hline 5 & Temperature $(-) 25^{\circ} \mathrm{C}$ & 0.9 & 0.5 \\
\hline 6 & Temperature $(+) 35^{\circ} \mathrm{C}$ & 1.1 & 0.9 \\
\hline
\end{tabular}


Table-6: System Suitability Parameters for Sitagliptin and Ertugliflozin

\begin{tabular}{|l|l|l|l|l|l|l|l|}
\hline S.no & \multicolumn{2}{|l}{ Sitagliptin } & \multicolumn{2}{l}{ Ertugliflozin } \\
\hline Inj & RT(min) & USP Plate Count & Tailing & RT(min) & USP Plate Count & Tailing & Resolution \\
\hline $\mathbf{1}$ & 2.139 & 4296 & 1.52 & 2.712 & 4466 & 1.22 & 3.9 \\
\hline $\mathbf{2}$ & 2.140 & 4266 & 1.52 & 2.714 & 4489 & 1.22 & 3.9 \\
\hline $\mathbf{3}$ & 2.141 & 4395 & 1.50 & 2.715 & 4627 & 1.22 & 4.0 \\
\hline $\mathbf{4}$ & 2.150 & 4675 & 1.47 & 2.719 & 4540 & 1.24 & 3.7 \\
\hline $\mathbf{5}$ & 2.150 & 4677 & 1.47 & 2.719 & 4516 & 1.23 & 3.7 \\
\hline $\mathbf{6}$ & 2.151 & 4957 & 1.46 & 2.722 & 4599 & 1.23 & 3.8 \\
\hline
\end{tabular}

Table-7: Assay Results of Sitagliptin and Ertugliflozin

\begin{tabular}{|l|l|l|}
\hline S.no & \% Assay Sitagliptin & \%Assay Ertugliflozin \\
\hline $\mathbf{1}$ & 99.47 & 99.51 \\
\hline $\mathbf{2}$ & 99.63 & 99.06 \\
\hline $\mathbf{3}$ & 98.46 & 100.83 \\
\hline $\mathbf{4}$ & 99.31 & 99.77 \\
\hline $\mathbf{5}$ & 98.32 & 100.34 \\
\hline $\mathbf{6}$ & 100.02 & 100.54 \\
\hline Avg & 99.20 & 100.01 \\
\hline Stdev & 0.7 & 0.68 \\
\hline \% RSD & 0.7 & 0.7 \\
\hline
\end{tabular}

Table-8: Degradation data for Sitagliptin and Ertugliflozin

\begin{tabular}{|l|l|l|l|l|l|l|}
\hline \multirow{2}{*}{$\begin{array}{l}\text { Type of } \\
\text { degradation }\end{array}$} & \multicolumn{2}{l}{ Sitagliptin } & Ertugliflozin \\
\cline { 2 - 7 } & Area & \%Recovered & \% Degraded & Area & \%Recovered & \% Degraded \\
\hline Acid & 2665162 & 93.83 & 6.17 & 354181 & 93.88 & 6.12 \\
\hline Base & 2708437 & 95.35 & 4.65 & 359368 & 95.26 & 4.74 \\
\hline Peroxide & 2727122 & 96.01 & 3.99 & 361816 & 95.91 & 4.09 \\
\hline Thermal & 2768901 & 97.48 & 2.52 & 366383 & 97.12 & 2.88 \\
\hline Uv & 2784928 & 98.05 & 1.95 & 370129 & 98.11 & 1.89 \\
\hline Water & 2806313 & 98.80 & 1.20 & 374029 & 99.15 & 0.85 \\
\hline
\end{tabular}

\section{REFERENCES}

1. B.K Sharma, Instrumental methods of chemical analysis, Introduction to analytical chemistry, $23^{\text {rd }}$ Edition Goel publication , Meerut, (2007)

2. Gurdeep R.Chatwal, Sham K .Anand, Instrumental Methods of Chemical Analysis, Pg 2.566-2.638 (2007)

3. K. D. Tripathi, Essentials of Medical Pharmacology, $6^{\text {th }}$ Edition, Jaypee brother's medical publishers (P) LTD, p254-255.

4. Indian Pharmacopoeia, Indian Pharmacopoeial Commission, Controller of Publication, Government of India, Ministry of health and Family Welfare, Ghaziabad, India, 2 (2010) 1657-1658.

5. https://www.scbt.com/scbt/product/Ertugliflozin-461432-26-8.

6. https://pubchem.ncbi.nlm.nih.gov/compound/Ertugliflozin.

7. https://en.wikipedia.org/wiki/Ertugliflozin.

8. $\quad$ https://www.drugbank.ca/drugs/DB01261.

9. https://www.scbt.com/scbt/product/Sitagliptin-361442-04-8.

10. https://en.wikipedia.org/wiki/sitagliptin

11. https://pubchem.ncbi.nlm.nih.gov/compound/sitagliptin

12. M. Laxmi, R . V. Valli Kumar et al.., Rp-Hplc Method Development And Validation For Simultaneous Estimation Of Ertugliflozin And Sitagliptin In Bulk And Tablet Dosage Forms, Indian Journal Of Applied Research 2019, 9(10).

13. P.Venkateshwar rao,A. lakshmana rao, S.V.U.M Prasad. A new stability indicating rp-hplc method for simultaneous estimation of ertugliflozin and sitagliptin in bulk and pharmaceutical dosage form its validation as per ich guidelines. IAJPS 2018; 05 (04); 2616-2627.

14. D. China Babu, C. Madhusudhana Chetty2 and S. K. Mastanamma. Novel Stress Indicating RP-HPLC Method Development and Validation for the Simultaneous Estimation of Ertugliflozin and Sitagliptin in Bulk and its Formulation. Orientjchem 2018;34(05).

15. HarshalathaP, Kothapalli Bannoth Chandrasekhar and Chandrasekhar MV. A novel RP-HPLC method for simultaneous determination of Ertugliflozin and Sitagliptin in bulk and tablet dosage form 2018; 9(3); 1042-1050 